\title{
Modelling Information Flow of Occupant Feedback in Office Buildings
}

\author{
D. $\operatorname{Artan}^{\text {a }}$, D. Donmez ${ }^{\mathrm{a}}$, I. Tekce ${ }^{\mathrm{b}}$ and E. Ergen ${ }^{\mathrm{a}}$ \\ ${ }^{a}$ Department of Civil Engineering, Istanbul Technical University, Turkey \\ ${ }^{b}$ Department of Architecture, Ozyegin University, Turkey \\ E-mail: artande@itu.edu.tr, ddonmez@itu.edu.tr, isilay.tekce@ozyegin.edu.tr, esin.ergen@itu.edu.tr
}

\begin{abstract}
Occupant comfort plays an important role in office buildings in terms of environmental, social, and economic aspects. Facility managers need to evaluate occupant feedback to moderate the negative consequences on office users and ultimately on the corporations that occupy office spaces. However, in the current facility management systems, occupant feedback is not effectively collected and evaluated; thus, facility managers cannot utilize this information in making critical decisions when operating, maintaining and retrofitting office facilities.
\end{abstract}

This paper presents the initial results of an ongoing research study, which focuses on integrating occupant feedback with Building Information Model (BIM) for assisting decision-makers in the facility management phase. The first step of this research study was to identify the information items that are required to represent occupant feedback for effective use in the facility management phase. To identify the required information items, interviews were performed with office users at ten office buildings and use cases were developed. To validate the use cases, interviews were performed with twelve facility managers. The aim of this paper is to present a sample of the use cases developed and describe the occupant feedback information flow observed in the office buildings. The results show that the occupant feedback data include detailed information related to: (1) location where the problem is observed, which is represented by building, and/or floor, and/or room, and/or façade, and/or table/zone/region depending on the case; (2) location of the user, that is represented by building, floor, room, table/zone/region, (3) source of the problem that is represented by type of building element and related building element, (4) source location, which specifies the location of a problem source that is different than the location where the problem is observed, and (5) time.

Keywords - Occupant Comfort; Facility Management; FM; Building Information Modeling; BIM; Use Case.

\section{Introduction}

Effective utilization of occupant complaints and feedback is crucial for successful operation, maintenance and retrofitting in offices. Many studies reveal the effects of occupant comfort on energy efficiency [1]; [2]; [3]; [4], employee health and well-being [5]; [6]; [7]; [8]; [9] and employee productivity [10]; [11]; [12]; [13]; [14]; [15]. Currently, to regulate indoor environment during design, operation and retrofitting in office buildings, occupant comfort standards (e.g., ASHRAE 55, EN ISO 7730) are used [16]. However, due to the variations in individuals' sensation levels, there is a poor relation between comfort conditions defined in the standards and the comfort conditions perceived by the occupants [17]. Occupant comfort and satisfaction increases when the occupant evaluations on performance parameters, such as thermal, visual, acoustic comfort, are considered by facility managers [18]; [19]. To measure functional comfort and identify possible workspace features which slows down or demotivates employees, collection of feedback from occupants is critical [20].

Collection of occupant feedback is currently performed by post occupancy evaluation (POE) tools, which are a type of building performance evaluation system. POE is defined as the "examination of the effectiveness for human users of occupied designed environment" [21]; [22]. The current POE tools, however, are lacking extensive inquiry about occupant satisfaction parameters [23]; [24], location based (spatial) occupant feedback [25] and easily understandable visualized data analysis and representation formats for facilities management (FM) [26]; [27].

Building Information Modeling (BIM) constitutes an effective platform to represent and analyze occupant feedback in facilities management. Although the need for $\mathrm{BIM}$ in facility management (FM) has been acknowledged by researchers and practitioners [28]; [29]; [30]; [31]; [32] BIM is still not being effectively utilized in this phase, including retrofitting activities [33]; [34]; [35]. FM is still dominated by corrective maintenance 
and there is under-utilization of preventive, predictive, and condition-based maintenance in facility management despite the use of advanced FM programs [36].

The study explained in this paper proposes to integrate BIM and occupant feedback to assist facility managers in making critical decisions in FM, including retrofitting activities, as well as preventive, predictive, and condition-based maintenance in office buildings. The first step of this ongoing study was to identify the information items that are required to represent occupant feedback for effective use in the FM phase. To identify the required information items, interviews were performed with office users at ten offices and use cases were developed based on those interviews. The aim of this paper is to present a sample of the use cases developed and to give an overview of the information items required to represent occupant feedback in the office buildings.

\section{Literature Review}

As part of the literature review occupant comfort, post occupancy evaluation (POE) and its relation to FM, existing POE tools, and FM \& BIM \& POE integration topics are investigated.

\subsection{Occupant Comfort}

There are three basic pillars of the effects of occupant comfort in office buildings. These are social, economic and environmental dimensions. The social dimension includes the well-being and health of employees. It is proved that the well-being and health of employees are directly related with the work environment comfort conditions [37]. One of the main disruptions among the employees is caused by indoor air quality. Adequate ventilation, pollutants and moisture level in the air are the key factors affecting the employee health in an office environment. Also, lighting, high level of noise and vibrations directly affects the employee's psychology. As a result, disturbing environmental conditions slows down the work rate of employees and increases the amount of mistakes due to distraction. It is observed that the absenteeism rate due to health issues is lower in offices which satisfy occupant needs; therefore, the employee productivity in such offices is comparably higher [38]; [39]; [40]. Design-related comfort aspects such as indoor air quality, noise control, thermal comfort, privacy, lighting comfort, spatial comfort and noise comfort designate the level of employee performance. It should be highlighted that physical environment of the office affects $15-20 \%$ of productivity of personnel; therefore, productivity constitutes the economical aspect of comfort condition by eventually affecting the company financialwise [41]; [42]; [37]. The environmental effects of occupant comfort level are also investigated in the literature. It has been identified that the occupant comfort dissatisfaction leads to inefficient use of building systems and causes an increase in building's energy consumption [18]. If the environment is designed to meet the requirements of the occupants and if the occupants understand how the building operates and how the controls systems are used, then it is possible for the occupants to contribute to lower building energy use [18]; [19]; [43]; [44].

The occupant comfort condition standards are used to regulate the indoor environment during operation and renovation periods of office buildings; however. There is a poor relation between comfort conditions defined in the standards and the comfort conditions perceived by the occupants since the sensation level of every individual is different [17]. Especially the evaluations of occupant feedback on performance parameters such as thermal, visual, acoustic comfort, indoor air quality, space usage and occupant control increases the occupant satisfaction [18]; [19]. Collection of feedback from users is vital to measure functional comfort and to identify possible workspace features which slows down or demotivates employees [20].

\subsection{Post Occupancy Evaluation (POE)}

During the occupancy phase of the buildings, the building performance evaluations (BPE) are conducted via post occupancy evaluation (POE) tools. Postoccupancy evaluation (POE) is the process of obtaining feedback on a building's performance after it has been built and occupied. In the literature, POE tools are named as Occupant Satisfaction Measurement Tools, Indoor Environmental Surveys or Building Performance Evaluation Surveys. By collecting factors, such as energy consumption, building use, maintenance costs or user satisfaction, POE allows various and continuous improvement possibilities in buildings. Moreover, because of the advances in technology, POE transformed into a knowledge tool than a diagnostic tool in time. Generally POE tools consist of three core parts: questionnaires, bills and metrics, physical measurements (optional) [45]. The results of the questionnaire surveys enable the determination of indirect parameters and characteristics, such as individual characteristics of the occupants and their personality. The physical measurement enable the determination of direct parameters, such as air temperature, relative humidity, air velocity, globe temperature, $\mathrm{CO}_{2}$ concentration, illuminance levels etc. Also, bills and metrics include documents related to energy consumption of the building and blueprints of the building.

\subsection{Importance of $\mathrm{POE}$ in $\mathrm{FM}$}

British Institute of Facilities Management has defined 
FM as "the integration of processes within an organization to maintain and develop the agreed services, which support and improve the effectiveness of its primary activities" [46]. Facility planning (space management); health, safety, security; maintenance management; and work environment comfort conditions are the main aspects of FM, in which cleaning services, support services, property services, catering services, security services, etc. are provided.

In the current FM applications, IT systems are effectively used in many service areas, such as maintenance and space management. However; work environment comfort conditions are only detected via sensors and POE is not integrated with this data. FM receives the occupant feedback not as a continuous information source, but only as the source of some work orders, which are supposed to be closed after fulfilling required maintenance. In fact, occupant feedback plays an important role for the management of work environment comfort conditions by the facility managers, and there is a need for advanced approaches for effective collection of occupant feedback data.

\subsection{Existing POE Tools}

There are many POE tools developed over the years focusing on different building types. Various methods and techniques were developed to extract user requirements regarding safety, health, comfort, functionality and efficiency, and aesthetic quality of buildings, and to identify defects in the system [47]. POEs are powerful tools for demonstrating whether or not building programs are delivering best value and for identifying areas for improvement. Currently, architects, built environment professionals, industry bodies and even clients prefer building evaluations through POE since they can see the benefits of evidence-based decision making in achieving their organizational goals. However the current POE tools are lacking some crucial features such as (1) extensive inquiry about occupant satisfaction parameters, (2) spatial occupant feedback, and (3) visualized representation of easily understandable data analysis results.

1. In POE measurement graphs, there is no extensive inquiry about occupant satisfaction parameters which are the indicative of occupant satisfaction. In the research studies, it is found that the satisfaction level of the occupants is measured using several parameters, but the dissatisfaction of the occupant or the reason of the complaint is not interrogated [23]; [24]. Lack of details constitutes a problem in case of a need for detection of specific problems.

2. The evaluation tools are not collecting spatial occupant feedback. The spatial information can enrich the feedback data and point out the building element related to the complaint. This information cannot be delivered to decision makers; therefore, a historical occupant feedback platform does not exist. It is known that linking the performance data to occupant location increases the system efficiency [25]. In a previous study, Hua et al. (2014; 2015) linked the occupant feedback to building spaces (i.e., rooms). However, this approach is not sufficient for open office environments and homogenous evaluations cannot be performed since usually open offices are large areas. Also, it is not possible to give feedback about the common areas other than offices.

3. There is lack of data analysis and representation of analysis results in the systems. In the current systems, the data obtained from evaluation system is not reflected in the facility management application [26]. The greatest obstacle is that the data is not processed and analyzed in a way that the decision makers need and not presented in an easily accessible, refined and visualized way [27]; [26].

\subsection{FM \& BIM \& POE Integration}

BIM is a process which uses $3 \mathrm{D}$, parametric and object-based models to create, store and use coordinated and compatible data throughout the life cycle of a facility [48]. The system goes beyond a visual modeling by means of $3 \mathrm{D}$ numerical modeling feature. It is a multifunctional management and information exchange tool which can contain all the information for manufacturing. Also, the information embedded in BIM models can be used for the operation of the facility [49]. Thanks to the developed exchange formats such as IFC Standards, data exchange between BIM tools is possible [50]. BIM integrated FM systems utilize effective decision making during operation and retrofit phases and consequently increases the building performance and occupant satisfaction [51]. The usage of BIM in FM bridges the information gap between the authorities in design and construction phase and the owner. It helps to reduce the costs since the data is ready to use and easy to reach in the model. Also, the models can be integrated into building automation systems which helps the FM to manage the buildings more effectively. Lastly, by enabling faster analysis and correction of problems, it helps to improve building performance and therefore the occupant comfort. In recent years, it has been emphasized that a BIM-integrated FM system is needed for delivering facility performance data more effectively to decisionmakers in FM or retrofitting processes [25]; [52]; [53]; [54]; [55]; [56]. The application of such a system is not reported in any of the studies, even though the required approaches are proposed frequently. 


\section{Method}

To identify the information items that are required to represent occupant feedback, the current information flow between employees and facility managers are investigated for reporting of complaints and feedback. A set of interviews were performed and use case scenarios were developed based on these interviews. Ten office employees, who work in ten offices in different companies, participated in the interviews. All office buildings chosen for the study have automation systems for HVAC control and operated by professional FM firms, but are diverse in terms of size, type of offices (cellular/open-plan), type of activities, facades, finishing materials, energy efficiency levels and none of them have BIM models. All the office users were asked four openended questions;

1. What kind of complaints did you report before?

2. Whom did you report your complaint?

3. Which communication method(s) did you use to report your complaint?

4. Which information did you provide to the authorities about your complaint?

According to the information obtained during the interviews, thirteen use case scenarios that represent occupant feedback/complaint information flow were developed. For each use case scenario, a use case diagram using Unified Modeling Language (UML) was created.

To validate the use cases that were developed, use case scenarios and UML diagrams were presented to twelve facility managers. Their feedback was received via interviews and reflected in the use cases. The methodology is also shown in Figure 1.

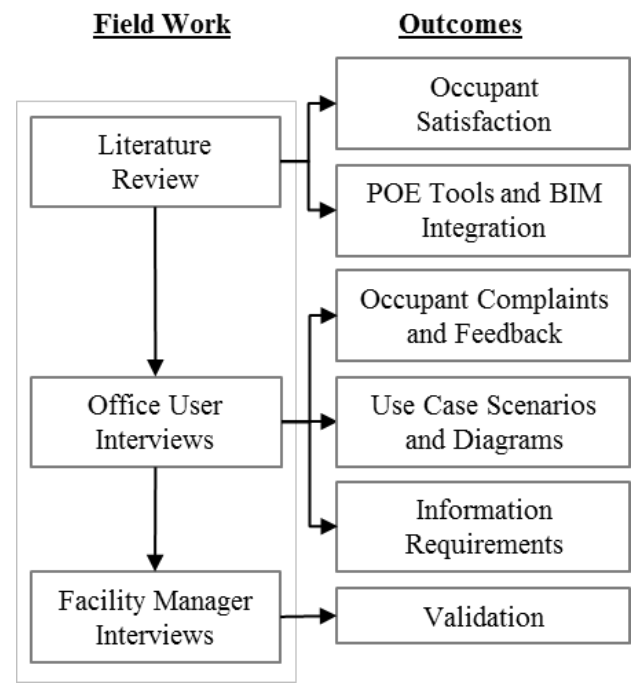

Figure 1. Methodology flowchart

\section{Results}

Out of thirteen use cases that were developed via interviews with office occupants and facility managers, three of them are provided as a sample in this paper. Information requirements that were identified from the use case as an outcome were presented along with each use case scenario.

\section{Use Case Scenario 1 : Indoor Air Quality - Odor}

Actors: Employee, facility manager, technical staff

Triggers: The employee realizes that there is an unpleasant odor in the office coming from the cafeteria.

Scenario: The employee realizes that there is a bad smell in the office coming from the cafeteria. He calls the facility manager and complains about it. The facility manager directs a technical staff team to the entrance floor to make an inspection about the complaint. After the inspection, the technical staff offers the construction of an automated door between the Blue Zone (offices) and the corridor that opens to the cafeteria. The facility manager accepts the offer and as a solution the door is constructed.

Outcomes: Building, Floor, Zone, and Source Location (different room for problem source, ex: cafeteria)

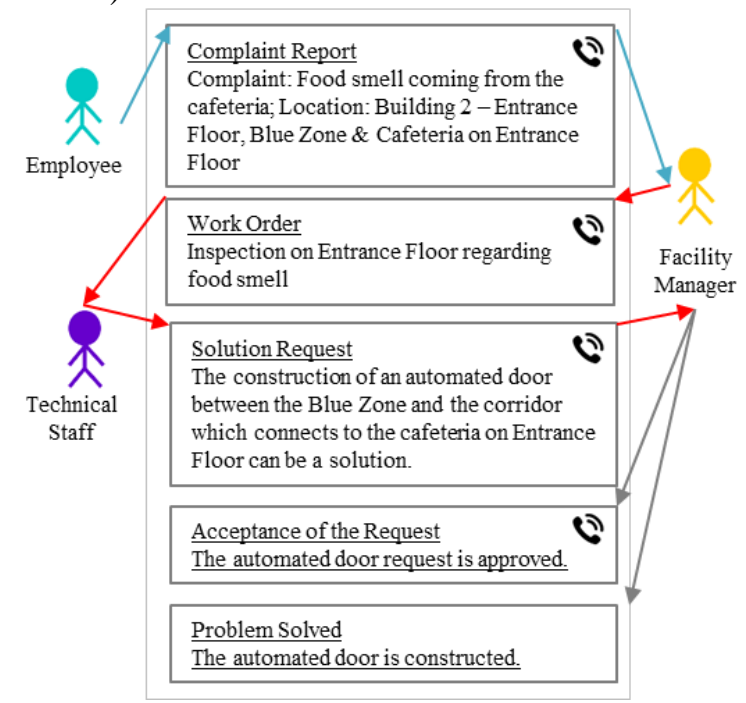

Figure 2. UML diagram of use case scenario 1

\section{Use Case Scenario 2: Visual Comfort - Reflection}

Actors: Employee, facility manager, administrative affairs manager

Triggers: The sunlight is reflecting on the computer of the employee and the employee cannot see his screen

Scenario: The sunlight is reflecting on the computer of the employee and the employee cannot see his screen. 
He reports this problem to the facility manager. The facility manager comes to the office of the employee and inspects the problem on site. After identifying that the problem is observed between 11:00 and 15:00, the facility manager decides that there is a need for a window shade. The facility manager calls the administrative affairs manager, reports the problem and requests a window shade for office $X$. The administrative affairs manager accepts the request of window shade procurement. The facility manager purchases the window shade. By using the window shade, the employee prevented reflection on his screen between 11:00 and 15:00 while working at his computer.

Outcomes: Floor, Room, Region, Table, Facade, Time.

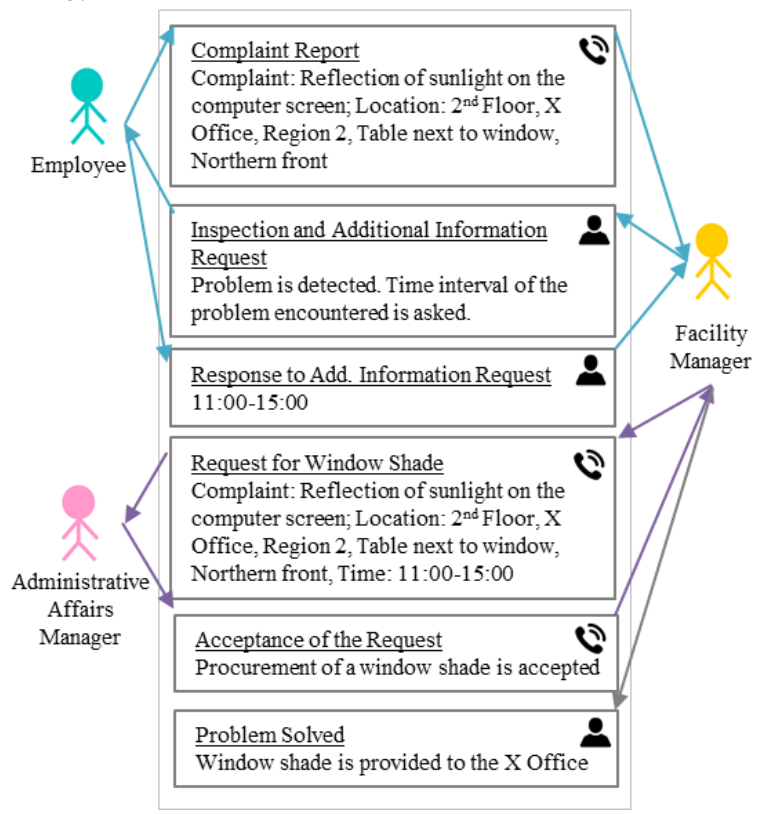

Figure 3. UML diagram of use case scenario 2

\section{Use Case Scenario 3: Indoor Air Quality - Odor}

Actors: Employee, facility manager, technical staff

Triggers: The employee thinks there is a bad smell coming from the air-conditioning (AC)

Scenario: The employee reports his complaint via a phone call about the unpleasant odor coming from airconditioning to the facility. The facility manager directs a technical staff to do an inspection. The technical staff changes the filter in the air-conditioning unit and reports back to facility manager. The facility manager notifies the employee about the maintenance work.

Outcomes: Floor, Room, Building Element Type, Related Building Element (Building Element Location)

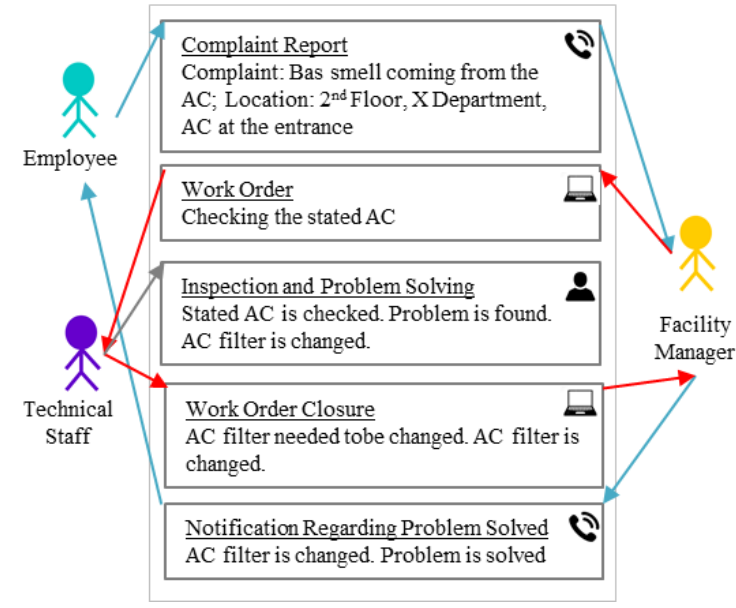

Figure 4. UML diagram of use case scenario 3

The use cases demonstrate that information requirements are different for each case. From use case scenario-1, building, floor, zone, and source location outcomes are obtained. Building, floor and zone represent the different granularity of location information of problem. The source location specifies the location of a problem source that is different than the location of the occupant. In the case of the unpleasant food smell in the office area, cafeteria represents the source location whereas the office represents the room/zone/region where the office user works.

From use case scenario-2 floor, room, region, table, facade, and time information requirements are gathered. Floor, room, region and table represent the location of the user. Since the complaint is related with a certain building frontage, the façade where the problem is observed is needed as well. Lastly, time stamp is important since the complaint is time dependent.

The information outcomes of the use case scenario- 3 are floor, room, building element type, and related building element (building element location). Floor and room gives information regarding user location. Since the complaint is related to a certain building element, the type and exact location of it are needed as well.

Table 1. Information requirement outcomes of use case scenarios

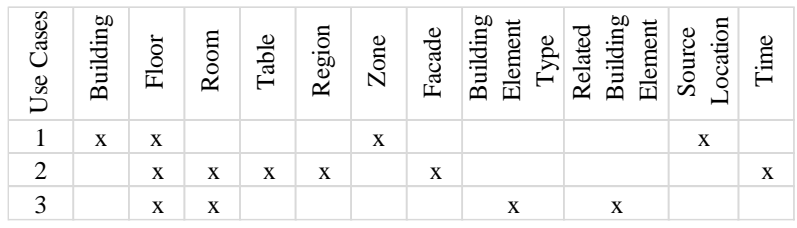


Information requirements gathered from the use case scenarios are summarized and listed below:

- Location where the problem is observed (represented by building, and/or floor, and/or room, and/or façade, and/or table/zone/region depending on the case)

- Location of the user (represented by building, floor, room, table/zone/region)

- $\quad$ Source of the problem

- Type of Building Element

- Related Building Element

- $\quad$ Source Location

- $\quad$ Time

\section{Conclusion}

This paper presents the initial results of an ongoing research study, which focuses on integrating occupant feedback with Building Information Model (BIM) for assisting decision-makers in the facility management phase. The first step of this research study was to identify the information items that are required to represent occupant feedback for effective use in the facility management phase. The aim of this paper is to present a sample of the use cases developed to identify the required information items and describe the occupant feedback information flow observed in the office buildings.

The use cases demonstrate that information requirements are different for each case. The identified information items are: (1) location where the problem is observed, which is represented by building, and/or floor, and/or room, and/or façade, and/or table/zone/region depending on the case; (2) location of the user, that is represented by building, floor, room, table/zone/region, (3) source of the problem that is represented by type of building element and related building element, (4) source location, which specifies the location of a problem source that is different than the location where the problem is observed, and (5) time.

The next step of this study is to determine how the required information items are represented in IFC and if necessary, how IFC should be extended to represent those information items. Future work includes developing a prototype that collects occupant feedback from the user, stores in BIM and presents to the decisionmakers for effective facility management.

\section{Acknowledgement}

This study was funded by the Scientific and Technological Research Council of Turkey (TUBITAK) (Grant \#116M177). Authors would like to thank TUBITAK for their support.

\section{References}

[1] M. Liu, Y. Zhu, B. Park, D. E. Claridge and D. K. Feary, "Airflow reduction to improve building comfort and reduce building energy consumptiona case study," ASHRAE Transactions, pp. 105, 384, 1999.

[2] E. Azar and C. Menassa, "Optimizing the Performance of Energy-Intensive Commercial Buildings: Occupancy-Focused Data Collection and Analysis Approach," J. Comput. Civ. Eng., pp. 10.1061/(ASCE)CP.1943-5487.0000521, C4015002, 2015.

[3] P. Shrestha and P. Kulkarni, "Factors Influencing Energy Consumption of Energy Star and NonEnergy Star Homes," Journal, pp. 29 (3), 269278, 2013.

[4] J. Day and . D. E. Gunderson, "Understanding high performance buildings: The link between occupant knowledge of passive design systems, corresponding behaviors, occupant comfort and environmental satisfaction," Building and Environment, pp. 84, 114-124., 2015.

[5] H. Brightman, D. Milton, D. Wypij, H. Burge and J. Spengler, "Evaluating building-related symptoms using the US EPA BASE study results," Indoor air, pp. 18(4), 335-345, 2008.

[6] . W. Fisk and O. Seppanen, "Providing better indoor environmental quality brings economic benefits," Lawrence Berkeley National Laboratory, 2007.

[7] . W. J. Fisk, . A. G. Mirer and M. J. Mendell, "Quantitative relationship of sick building syndrome symptoms with ventilation rates," Indoor air, pp. 19(2), 159-165, 2009.

[8] . M. J. Mendell and A. Mirer, "Indoor thermal factors and symptoms in office workers: findings from the US EPA BASE study," Indoor air, pp. 19(4), 291-302, 2009.

[9] J. C. Vischer, "Towards an environmental psychology of workspace: How people are affected by environments for work," Architectural science review, pp. 51(2), 97-108., 2008.

[10] R. Kosonen and F. Tan, "Assessment of productivity loss in air-conditioned buildings using PMV index.," Energy and buildings, pp. 36(10), 987-993, 2004.

[11] A. Rosenfeld and W. Fisk, "Estimates of improved productivity and health from better indoor environments," Indoor air, pp. 7(3), 158172, 1997.

[12] O. Seppänen and W. Fisk, "Some quantitative relations between indoor environmental quality 
and work performance or health," Hvac\&R Research, pp. 12(4), 957-973, 2006.

[13] P. Wargocki, J. Andersson, A. Boestra, D. Clements-Croome, K. Fitzner and S. Hanssen, "Indoor climate and productivity in offices: How to integrate productivity in life cycle costs analysis of building services.," 2006.

[14] P. Wargocki and R. Djukanovic, "Simulations of the Potential Revenue from Investment in Improved Indoor Air Quality in an Office Building," ASHRAE Transactions, p. 111(2), 2005.

[15] D. Wyon, "Indoor environmental effects on productivity," Paths to Better Building Environments,ASHRAE, 1997.

[16] P. Antoniadou and A. M. Papadopoulos , "Occupants' thermal comfort: State of the art and the prospects ofpersonalized assessment in office buildings," Energy and Buildings, p. 153 (2017) 136-149, 2017.

[17] A. Wagner, E. Gossauer, C. Moosmann, T. Gropp and R. Leonhart, "Thermal comfort and workplace occupant satisfaction-results of field studies in german low energy office buildings," Energy Build., pp. 39(7), 758-769, 2007.

[18] F. Jazizadeh, A. Ghahramani, B. Becerik-Gerber, T. Kichkaylo and M. Orosz, "'Human-Building Interaction Framework for Personalized Thermal Comfort-Driven Systems in Office Buildings," $J$. Comput. Civ. Eng, pp. 28 (1), 2-16., 2014.

[19] E. Azar and C. Menassa, "Optimizing the Performance of Energy-Intensive Commercial Buildings: Occupancy-Focused Data Collection and Analysis Approach," J. Comput. Civ. Eng, pp. 10.1061/(ASCE)CP.1943-5487.0000521, C4015002., 2015.

[20] S. Mallory-Hill, W. F. Preiser and C. Watson, Enhancing Builidng Performance, West Sussex, UK: Wiley-Blackwell, 2012.

[21] C. M. Zimring and J. E. Reizenstein, "PostOccupancy Evaluation-An Overview," Sage Journals, pp. Volume: 12 issue: 4, page(s): 429450, 1980.

[22] P. Croates, Z. Öztürk and Y. Arayici, "Post occupancy evaluation (POE) in residential buildings utilizing BIM and sensing devices: Salford energy house example".," Retrofit, 2012.

[23] S. Turpin-Brooks and G. Viccars, "The development of robust methods of post occupancy evaluation," Facilities, pp. 24 (5/6),177-196, 2006.
[24] L. Chiu, R. Raslan, H. Altamirano-Medina, J. Wingfield and R. Lowe, "A socio-technical approach to post-occupancy evaluation: interactive adaptability in domestic retrofit," Building Research \& Information, pp. 42 (5), 574590, 2014.

[25] Y. Hua, Ö. Göçer and K. Göçer, "Spatial mapping of occupant satisfaction and indoor environment quality in a LEED platinum campus building," Building and Environment, pp. 79, 124-137, 2014.

[26] I. Motawa and A. Almarshad, "A knowledgebased BIM system for building maintenance," Automation in Construction, pp. 29 (1), 173-182, 2013.

[27] A. Motamedi, A. Hammad and Y. Ase, "Knowledge-assisted BIM-based visual analytics for failure root cause detection in facilities management," Automation in Construction, pp. 43, 7, 73-83, 2014.

[28] A. Hayes, N. Shetty, D. Pocock and J. Watts, "Leveraging the Relationship between BIM and Asset Management," , Institution of Civil Engineers (ICE); , Chartered Institution of Civil Engineering Surveyor (ICES); , Institute of Asset Management (IAM).; 2015.

[29] A. Akcamete, B. Akinci and J. J. Garrett, "Potential utilization of building models for planning maintenance activities," in Proceedings of the International Conference on Computing in Civil and Building Engineering (ICCCBE, Nottingham, 2010.

[30] B. Becerik-Gerber and K. Kensek, "Building information modelling in architectur eengineering, and construction: emerging research directions and trends," Journal of Professional Issues in Engineering Education and Practice, vol. 3, no. 136, pp. 139-147, 2010.

[31] P. Parsanezhad and J. Dimyadi, "Effective facility management and operations via a BIM- based integrated information system," in Proceedings of the CIB Facilities Management Conference, Copenhagen, 2014.

[32] R. Volk, R. Stengel and F. Schultmann, "Building information modelling (BIM) for existing buildings: literature review and future needs," Automation in Construction, no. 38, pp. 109-127, 2014.

[33] D. Ilter and E. Ergen, "BIM for building refurbishment and maintenance: current status and research directions," Structural Survey, vol. 3, no. 33, pp. 228-256, 2015.

[34] B. Becerik-Gerber, F. Jazizadeh, N. Li and G. Calis, "Application areas and data requirements 
for BIM-enabled facilities management," $J$. Constr. Eng. Manage, vol. 3, no. 138, pp. 431442, 2012.

[35] R. Eadie, M. Browne, H. Odeyinka, C. McKeown and S. McNiff, "BIM implementation throughout the UK construction project lifecycle: an analysis," Automation in Construction, no. 36, pp. 145-151, 2013.

[36] X. Yang and S. Ergan, "BIM for FM: Information Requirements to Support HVAC-Related Corrective Maintenance," J. Archit. Eng, p. 23(4): 04017023, 2017.

[37] D. Stokols and F. Scharf, "Developing standardized tools for assessing employees' ratings of facility performance" In: G Davis and F T Ventre, Editors, Performance of Buildings and Serviceability of Facilities," American Society for Testing and Materials, pp. Philadelphia, PA, 55$68,1990$.

[38] S. Korkmaz, J. Messner, D. R. Riley and C. Magent, "High-Performance Green Building Design Process Modeling and Integrated Use of Visualization Tools," Journal of Architectural Engineering, pp. 16 (1), 37-45, 2010.

[39] S. E. Chidiac, E. J. C. Catania , E. Morofsky and S. Foo, "Effectiveness of single and multiple energy retrofit measures on the energy consumption of office buildings," Energy, pp. 36., 5037-5052, 2011.

[40] C. Candido, J. Kim, R. de Dear and Thomas L., "BOSSA: a multidimensional post-occupancy evaluation tool," Building Research \& Information, pp. 44:2,214-228, 2016.

[41] J. Rostron, Sick Building Syndrome: Concepts, Issues and Practice, London: Spon, 1997.

[42] R. V. and Burgun F., "Energy and Comfort Performance Evaluation after Renovation of an Office Building," in 26th Conference on Passive and Low Energy Architecture, Quebec City, Canada, 2009.

[43] Shrestha and Kulkarni, "Factors Influencing Energy Consumption of Energy Star and NonEnergy Star Homes," Journal of Management In Engineering, pp. 29(3), 269-278, 2013.

[44] J. K. Day and . D. E. Gunderson, "Understanding high performance buildings: The link between occupant knowledge of passive design systems, corresponding behaviors, occupant comfort and environmental satisfaction," Building and Environment, pp. 84: 114-124, 2015.

[45] P. Coates, Y. Arayici and Z. Ozturk, "New Concepts of Post Occupancy Evaluation (POE)
Utilizing BIM Benchmarking Techniques and Sensing Devices," in Sustainability in Energy and Buildings. Smart Innovation, Systems and Technologies, vol 12., Berlin, 2012.

[46] "Faciilities Management Introduction," The Professional Body for Facilities Management, 2017. [Online]. Available: http://www.bifm.org.uk/bifm/about/facilities.

[47] Y. Hua, "Understanding POE for future building practices," Intelligent Buildings International, pp. 5:3, 133-134, DOI: 10.1080/17508975.2013.811162, 2013.

[48] J. Rodriguez, "An Introduction to Building Information Modeling (BIM)," 09 October 2017. [Online]. Available: https://www.thebalance.com/introduction-tobuilding-information-modeling-bim- 845046 . [Accessed 15 January 2018].

[49] P. M. Teicholz, "BIM for Facility Managers," 2013.

[50] Glasgow Caledonian University, "Sustainable BIM-driven post occupancy evaluation for buildings," CIC Start Online feasibility study, Edinburg, Glasgow, 2012.

[51] . B. Becerik-Gerbe, . F. Jazizadeh, N. Li and G. Calis, "Application areas and data requirements for BIM-enabled facilities management," $J$. Constr. Eng. Manage., pp. 138,3, 431-442, 2012.

[52] . P. Coates, Y. Arayıc1 and Z. Özturk, "New concepts of POE utilizing BIM benchmarking techniques and sensing devices," in Sustainability in Energy and Building Proceedings of the 3rd International Conference., 2011.

[53] I. Motawa and W. Corrigan, "Sustainable BIMdriven post-occupancy evaluation for buildings," 2012. [Online]. Available: http://www.cicstart.org/fs49.htm. http://www.cicstart.org/wb49.htm..

[54] Z. Ozturk, Y. Arayici and P. Coates, "Post occupancy evaluation (POE) in residential buildings utilizing BIM and sensing devices: Salford energy house example," Retrofit, 2012.

[55] I. Motawa and K. Carter, "Sustainable BIM-based evaluation of buildings," Procedia Soc. Behav. Sci., pp. 74, 419, 2012.

[56] Y. Hua, K. Göçer and Ö. Göçer, "Completing the missing link in building design process: Enhancing post-occupancy evaluation method for effective feedback for building performance," Building and Environment, pp. 89, 14-27. 